الشركة السعودية للكهرباء

Saudi Electricity Company

\title{
Future Trends in Electricity Demand in Saudi Arabia and the Gulf Region
}




\section{About KAPSARC}

The King Abdullah Petroleum Studies and Research Center (KAPSARC) is a non-profit global institution dedicated to independent research into energy economics, policy, technology and the environment across all types of energy. KAPSARC's mandate is to advance the understanding of energy challenges and opportunities facing the world today and tomorrow, through unbiased, independent, and high-caliber research for the benefit of society. KAPSARC is located in Riyadh, Saudi Arabia.

This publication is also available in Arabic.

\section{Legal Notice}

(c) Copyright 2021 King Abdullah Petroleum Studies and Research Center ("KAPSARC"). This Document (and any information, data or materials contained therein) (the "Document") shall not be used without the proper attribution to KAPSARC. The Document shall not be reproduced, in whole or in part, without the written permission of KAPSARC. KAPSARC makes no warranty, representation or undertaking whether expressed or implied, nor does it assume any legal liability, whether direct or indirect, or responsibility for the accuracy, completeness, or usefulness of any information that is contained in the Document. Nothing in the Document constitutes or shall be implied to constitute advice, recommendation or option. The views and opinions expressed in this publication are those of the authors and do not necessarily reflect the official views or position of KAPSARC. 


\section{Key Points}

Many important factors are affecting electricity demand in Saudi Arabia and the Gulf Cooperation Council (GCC) region. Studies show that electricity consumption has grown rapidly in the past decades, driven by substantial population increases, regulated energy prices and economic growth.

The Saudi government has implemented several initiatives as part of Saudi Vision 2030 that will impact electricity production and demand. These initiatives include industrial development and localization; energy efficiency; and replacing liquid fuels in power generation with low-cost natural gas, solar energy and wind. The government has also implemented electricity price reforms.

Deep decarbonization and the electrification of industry and transportation will further impact electricity demand and energy system costs. The region's trends in electricity demand will also be shaped by other disruptive factors, such as electric vehicle (EV) deployment and green hydrogen production.

Energy efficiency is an important driver of future electricity demand trends. Moreover, energy price reforms have made energy efficiency mechanisms more attractive.

EV development in the GCC region may be fostered by several policies. These policies may also lessen some of the technical constraints related to EV charging on the power grid.

Low prices of renewables may position the region as a major green hydrogen producer by 2030 . The resulting increased exports of green hydrogen to Asia and Europe will increase electricity demand. 


\section{Background to the Workshop}

L

ong-term electricity demand projections are fundamental for power generation expansion planning and for broader energy policy formulation. Studies show that electricity demand in Saudi Arabia and the GCC region has been growing rapidly over the past decades. This growth has several drivers, including economic growth, increasing populations and regulated electricity tariffs. However, energy price reforms and broader structural changes within these economies, along with energy efficiency initiatives and the exodus of expatriates, is flattening electricity demand.

Against this backdrop, future trends in electricity demand are becoming less clear, creating challenges for the region's policymakers in setting efficient energy policies. Moreover, the region's electricity demand will be affected by several other disruptive factors going forward. The emergence of green hydrogen as a means of decarbonizing the energy supply and the deployment of EVs may further impact demand patterns. This workshop aimed to highlight the above-mentioned challenges of future demand trends and the driving and disruptive factors in two sessions.
The workshop's first session, “Electricity Demand Outlooks in the Gulf Cooperation Council Countries," was dedicated to answering the following questions:

What are the future electricity demand trends in the GCC region?

What factors are shaping future electricity demand patterns?

In the second session, "The Region's Electricity Demand Facing Disruptive Factors: Green Hydrogen and Electric Vehicles," experts from selected fields discussed the following questions:

What will the role of green hydrogen be in the GCC region's future power demand?

What conditions can foster EV deployment in the GCC region?

\footnotetext{
${ }^{1}$ The GCC comprises Bahrain, Kuwait, Qatar, Oman, Saudi Arabia and the United Arab Emirates.
} 


\section{Electricity Demand Outlook in GCC Countries}

$\mathbf{P}$ rojecting future electricity demand is an increasingly complex problem. Navigating overcapacity, which may cause stranded assets, and undercapacity, which may cause system failure, is critically important for policymakers. In the GCC region, electricity is also strategically important because the harsh weather conditions create high electricity demand for cooling. Against this backdrop, projecting future trends in demand is crucial for ensuring a reliable and affordable electricity supply in the region.

Globally, the power sector is experiencing substantial changes, driven by increasing electricity access and electrification. In this context, the panelists identified five factors, referred to as the "five Ds," that will drive future electricity demand patterns. They are disruptions to demand from emerging uses of electricity, decarbonization, the decentralization of distribution, the democratization of energy access and the digitalization of electricity uses.

Decarbonization efforts and climate commitments are increasing the share of renewable energy in total energy. Notably, the potential for renewable energy development is significant in the GCC region. For instance, the electrification of the transportation and water desalination sectors may significantly increase the region's electricity demand in the future.

Historically, electricity demand growth in Saudi Arabia and the GCC region has been driven primarily by population growth and increasing standards of living. However, recent policy-driven reforms have changed the relative weights of these demand drivers. Price reforms and efficiency measures are currently the main factors influencing electricity demand (Atalla and Hunt 2016; Aldubyan and Gasim 2020; Mikayilov et al. 2020). They are also expected to account for most changes in electricity demand going forward. Nonetheless, addressing market failures and barriers to fully benefitting from energy efficiency and price reforms requires multipronged efforts. Successful policies require appropriate institutions and regulations, the ability to capitalize on technical capacities, and information and awareness.

One major challenge facing the GCC region's power sector is meeting the demand for cooling while decarbonizing its underlying supply. In this region, cooling accounts for up to $70 \%$ of the electricity load. In Saudi Arabia, electricity demand growth will continue to be driven by the high energy requirements to cool buildings. The Kingdom's share of energy used for cooling ranks third in the G20, a group of leading rich and developing nations, after those of the United States and China.

Although these shares may change later, cooling is expected to remain a key driver of future electricity demand, with significant energy savings potential (Krarti et al. 2020). Globally, indirect emissions from electricity for space cooling may account for $18 \%$ of the total increase in global carbon dioxide emissions by 2050 . Moreover, room air conditioners alone will add about 165 gigatonnes of cumulative carbon dioxide-equivalent emissions by $2050,30 \%$ of which will come from refrigerants. These emissions will result in global warming of approximately 0.5 degrees Celsius by the year 2100 .

Accurately assessing the integration and deployment of continuously evolving technologies and policies is challenging. Integrated energy modeling, which can capture disruptive technologies, socioeconomic factors and other developmental priorities, is therefore necessary. Insights from integrated energy-economy models of 
Saudi electricity demand show that demand growth is likely to decelerate over the next decade. The sectoral breakdown is not expected to significantly change, as the residential sector will continue to comprise the largest portion of the demand. However, industrial and commercial demand will increase to a greater extent.

In a forthcoming study, KAPSARC researchers assess future trends in Saudi electricity demand. The results show that price reforms and energy efficiency can generate significant energy savings. Specifically, reforming electricity prices and implementing efficiency measures may reduce total demand between $11 \%$ to $32 \%$ by 2030 relative to the baseline of no reforms (Soummane and Ghersi 2021). This reduction in demand will, in turn, reduce generation, transmission and distribution capacity investment requirements. Furthermore, although reforming electricity prices and promoting efficient electricity use may be politically challenging to enforce, these efforts are not necessarily costly. If implemented correctly, they can generate macroeconomic gains by freeing up fuel used for power generation and reducing the burden of subsidies on public finance.
Finally, several uncertainties may alter future electricity demand patterns in Saudi Arabia and the GCC region. The economic and social structures of the GCC countries are transforming. These changes aim to diversify the sources of income (e.g., Vision 2030) and energy in the region. Moreover, large-scale projects (e.g., Neom city) and technological changes (e.g., the electrification of other energy uses) are underway. Finally, socioeconomic factors (e.g., population and housing dynamics) increase the uncertainties when designing power systems that are resilient to disruptive changes. 


\section{Disruptive Factors in the GCC Region's Electricity Demand: Green Hydrogen and EVs}

$\mathrm{T}$ The first disruptive factor in the GCC region's electricity demand outlook is green hydrogen. Hydrogen is increasingly emerging as a means of decarbonizing the energy supply. The use of green hydrogen, that is, hydrogen derived from renewable-generated electricity through electrolysis, is gaining momentum worldwide. It is used in a variety of sectors, from industrial processes (e.g., steel and refining) to transportation and power generation. Because the GCC countries have significant renewable resource endowments, the region may become a key player in the hydrogen industry over the coming decades. If so, the region's power generation will need to increase to meet the demand for green hydrogen.

The future of green hydrogen development in the GCC region hinges on the projected costs of electricity generation from renewable sources. Green hydrogen development is also consistent with the region's renewable energy targets. Currently, the levelized costs of solar electricity (LCOEs) in Saudi Arabia, the United Arab Emirates and Qatar are among the lowest worldwide. Recent tenders ranged from 1.35 to 1.61 cents per kilowatthour (kWh). In 2021, a solar photovoltaic project in Saudi Arabia achieved an LCOE of 1.04 cents $/ \mathrm{kWh}$. At this rate, green hydrogen is cheaper to produce than gray hydrogen (i.e., hydrogen from fossil fuel resources) and blue hydrogen (i.e., hydrogen from fossil fuel resources with carbon capture) are.

Based on the low LCOEs in the GCC, green hydrogen was originally expected to become competitive with gray and blue hydrogen by 2030 . The ground-breaking LCOE in Saudi Arabia may accelerate this goal. For example, green steel production in the GCC is expected to cost less than blast furnace steel in Europe does. Green hydrogen integration in the GCC will lead to a cost reduction of $10 \%$. Currently, the Kingdom's steel production is fully electrified (electric arc furnace-based). It consumes around 5 terawatthours (TWh) of electricity, or around $1.5 \%$ of the Kingdom's total annual consumption. Integrating green hydrogen into this production process could further increase the demand for electricity by 2030 .

The second disruptive factor in the region's electricity demand outlook is the potential large deployment of EVs to decarbonize the transport sector. EV penetration may create challenges for the power grid, as EVs will contribute a significant new load. From a global perspective, the stock of EVs may reach almost 250 million units by 2030 , up from approximately 8 million units currently. Thus, the demand for electricity for the EV stock may reach 1,000 TWh by 2030 .

Meeting this future electricity demand from EV deployment will be challenging. An EV is estimated to require around 3.8 megawatthours of electricity generation per year. Thus, large-scale EV deployment will require grid reinforcement, notably in regions with weak network infrastructures (mainly distribution networks). Models of the GCC region's power system show that EV penetration can help to flatten the load curve by reducing load variability throughout the day. However, price-driven mechanisms, such as time-of-use schemes and smart charging infrastructure, are critical to fully capture the benefits of EV integration within the grid. Given the GCC's climate, quick charging technologies for EV batteries may not work well during the summer. Finally, consumer behavior related to EV charging needs to be studied further. 


\section{References}

Aldubyan, Mohmmad, and Anwar Gasim. 2020. "Energy price reform in Saudi Arabia: Modeling the economic and environmental impacts and understanding the demand response." Energy Policy 148: 111941.

Atalla, Tarek N., and Lester C. Hunt. 2016. "Modelling residential electricity demand in the GCC countries." Energy Economics 59: 149-158.

Krarti, Moncef, Mohammad Aldubyan, and Eric Williams. 2020. "Residential building stock model for evaluating energy retrofit programs in Saudi Arabia." Energy 195: 116980.

Mikayilov, Jeyhun I., Abdulelah Darandary, Ryan Alyamani, Fakhri J. Hasanov, and Hatem Alatawi. 2020. "Regional heterogeneous drivers of electricity demand in Saudi Arabia: Modeling regional residential electricity demand." Energy Policy 146: 111796.

Soummane, Salaheddine, and Frédéric Ghersi. 2021. "Projecting Saudi Sectoral Electricity Demand in 2030 Using a Computable General Equilibrium Model.” KAPSARC. KS--2021--DP12. 


\section{About the Workshop}

This workshop was held virtually on March 31, 2021. Five experts came together to discuss future trends in electricity demand in Saudi Arabia and the GCC region.

\section{List of participants}

Ashok Sarkar - Senior Energy Specialist (Middle East, GCC and South Asia), World Bank Group

Fatima Alfoora Alshamsi - Energy Policy Executive Director, Department of Energy, Abu Dhabi

Shihab Elborai - Partner, Strategy\&, Middle East

Ahmed Elbermbali - Managing Director, Clean Energy Business Council, Middle East and North Africa

Ahmed Al-Balawi - Renewable and Energy Storage Research Group Leader, Saudi Electricity Company

All of the information in this brief is derived from the insights presented during the workshop. The panelists' presentations are available upon request. A full video recording of the workshop is available at this link. 


\section{Notes}

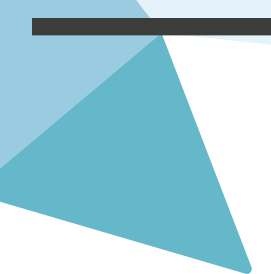




\section{About the Team}

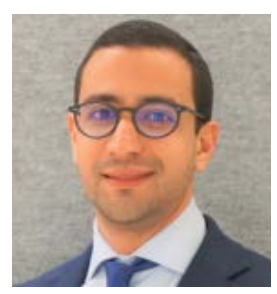

\section{Salaheddine Soummane}

Salaheddine is a research associate in KAPSARC's Energy Transitions and Electric Power program. His current research focuses on modeling the Saudi electricity market, including reforms and regulatory frameworks.

Before joining KAPSARC, Salaheddine worked as a research associate for the Centre for International Research on Environment and Development (CIRED), a National Centre for Scientific Research lab in Paris. He focused on integrated economy-energy modeling. He also worked as an economist researcher within the research and development department of Électricité de France (Paris), a utility group. He was part of the group's energy markets and environmental regulation unit, focused on emerging markets.

Salaheddine holds a Ph.D. in Economics from Paris-Saclay University (France). $\mathrm{He}$ holds an M.Sc. in Energy Economics from the University of Montpellier (France) and an M.Sc. in Finance from the Aix-Marseille School of Economics (France).

\section{About the Project}

The electricity sector is at the heart of many countries' energy transitions. Both the demand and supply sides of electricity markets must be rigorously assessed to identify appropriate policy options that yield maximum benefits for stakeholders. This project focuses on the demand side of the Saudi electricity market. Other KAPSARC projects are assessing the supply side, including the evolution of the power mix and the integration of the Saudi electricity market with regional markets.

Electricity demand in Saudi Arabia grew consistently for several decades. Since 2016, however, the country has initiated price reforms and rationalization campaigns for energy use to curb electricity demand and inefficient use. As a result, Saudi electricity demand flattened between 2016 and 2018 and dropped for the first time on record in 2019.

The factors of growth or decline in demand and the impact of energy efficiency on electricity demand in developing economies are not well understood. Nevertheless, understanding electricity demand growth is critical for public policy development. Uncertainty regarding electricity demand growth directly impacts investment needs. This project therefore disentangles the primary driving factors of Saudi electricity demand and analyzes potential future trends in electricity demand by sector. It also investigates the impacts of disruptive factors, such as EVs and green hydrogen production. 
INAPSARC

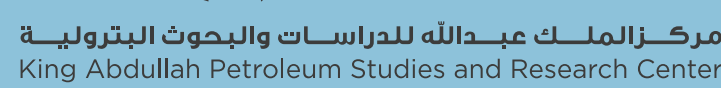

www.kapsarc.org 